\title{
Apontamentos sobre a Tradição Cultural do Ensino e do Aprendizado no Curso de Direito Brasileiro
}

\author{
Notes on the Cultural Tradition of Teaching and Learning in the \\ Brazilian Legal Education
}

\author{
Hector Luiz Martins Figueira ${ }^{1}$
}

\begin{abstract}
RESUMO
Este artigo parte da análise da cultura bacharelesca nos cursos jurídicos brasileiros. De um lado, verificar-se-á a forma como o conhecimento jurídico é concebido historicamente, construído e reproduzido atualmente por professores na universidade. De outro, serão apreciadas as éticas distintas presentes no ensino e na prática das atividades judiciárias. A metodologia de pesquisa é a etnografia, com descrição de dados qualitativos, a partir da impressão dos atores do campo jurídico educacional. Neste contexto, percebeu-se a presença de hierarquias dentro do ensino. Ora includentes, ora excludentes. Ainda, nota-se uma demanda por reconhecimento através da cultura de certificação, promovida por algumas universidades.
\end{abstract}

\section{PALAVRAS CHAVES:}

Ensino jurídico; cultura bacharelesca, demanda por reconhecimento; inclusão-excludente.

\begin{abstract}
This article aims to analyze the scholastic culture within the Brazilian legal education. On the one hand, it will be verified how legal knowledge is historically conceived, constructed and reproduced today by professors at the university. On the other hand, the different ethics present in the teaching and practice of judicial activities will be studied. The article will be based on the is ethnography - as its research methodology. In addition, there will be description of qualitative data, based on the impression of the actors in the educational legal field. In this context, it was noticed the presence of hierarchies within the way of teaching. Sometimes inclusive ones, sometimes excluding ones. Still, there is a demand for recognition through the culture of certification, promoted by some universities.
\end{abstract}

\section{KEYWORDS:}

Legal education; baccalaureate culture, demand for recognition; inclusion-excluding.

\footnotetext{
${ }^{1}$ Doutor e Mestre em Direito pela Universidade Veiga de Almeida, UVA/RJ. Advogado e professor da UNIFAA, FAMESC e EMERJ.
} 


\section{INTRODUÇÃO}

Este artigo perfaz o caminho de problematizar a tradicional cultura bacharelesca brasileira, em especial dos estudantes da graduação em Direito que buscam se graduar para ter a aprovação em concurso público em alguns casos e em outros, uma perspectiva de melhora social no cenário de uma sociedade desigual. Para estas reflexões analisei entrevistas que obtive com a pesquisa de campo oriunda da minha tese de doutorado defendida na Universidade Veiga de Almeida, intitulada "Tradição do ensino jurídico: representações de uma pedagogia do poder”. As observações concentraram-se nos alunos que já se encaminham para o final da graduação e já começam a buscar alternativas e ferramentas para complementar seus estudos realizados nos últimos cinco anos de formação, buscando uma inserção no mercado de trabalho e o tão sonhado diploma para virar "doutor".

Primeiramente, vale destacar que com o fito de servir à elite existente por aqui, a educação brasileira sofre influências liberais advindas da Europa, se moldando aos ideais dos poderosos da época. O que provocou o surgimento de um formato especial de liberalismo baseado nos interesses elitistas em detrimento de interesses populares. Desse modo, a cultura jurídica, política e econômica de viés autoritário predominou, mesmo com o advento da democracia. Nesse cenário, a educação, de uma maneira geral, foi se desenvolvendo, administrada por um Estado tutelador, afastado das instâncias populares, fruto de uma cultura bacharelesca. (VENÂNCIO FILHO, 2004)

Assim, me deparei com um problema ainda maior ao perceber que muitos estudantes recém-formados em Direito passavam a integrar um grupo de bacharéis sem expressão dentro no mercado de trabalho e continuavam na fila em busca por emprego. Mas por outro lado, a faculdade lhes proporcionava uma cidadania diferente dos demais que não tinham curso superior, realçando a hierarquia e a estratificação que a certificação promove nos contextos sociais e profissionais. Percebi, portanto, um fenômeno denominado de inclusão-excludente vivenciado por alunos egressos de cursos jurídicos.

Os objetivos deste trabalho se baseiam em compreender a cultura bacharelesca e como ela se desdobra no cenário atual de uma graduação em direito pesquisada no contexto do ensino 
jurídico privada carioca. Ainda perceber como a formação promove uma mobilidade no status cívico das pessoas que estão envolvidas neste processo e seus desdobramentos práticos e atuais advindos da observação participante e da descrição delas.

As reflexões se justificam, devido a constante ampliação do número de cidadãos portadoras de diploma de nível superior no Brasil é considerável e conhecida por meio de dados históricos coletados da trajetória profissionalizante que o país experimentou. No panorama geral, Elson Pires (1995) em sua tese de doutorado constatou que a matrícula em cursos superiores havia crescido a uma taxa de $344,64 \%$ no período $60 / 70,223,70 \%$ entre $70 / 80$ e $9,53 \%$ entre 81 e 89 . No período compreendido entre 1981 e 1990 a taxa de crescimento da População Economicamente Ativa - (PEA) que possuía segundo grau e superior completo foi de 91,46\%, o que aumentou ainda mais com o passar dos anos. (PIRES, 1995). No entanto, este crescimento parece ser particularmente acentuado para os cargos que envolvem o conhecimento do Direito em todos os níveis da federação. Afinal, o conhecimento jurídico é essencial para praticamente todas as carreiras públicas.

Para que estas impressões fossem colhidas e descritas, utilizei-me da pesquisa de matriz etnográfica. Para a realização da etnografia, fui a campo, como observador participante. Uma metodologia bastante rigorosa advinda da antropologia para dar conta de fazer as análises qualitativas. Era, portanto, necessário "saber ouvir, escutar, ver e fazer uso de todos os sentidos", bem como são necessárias tais regras para realizar o trabalho de campo, como: "aprender quando perguntar e quando não perguntar, assim como que perguntas fazer na hora certa”. (FOOTE-WHYTE, 1975, p. 303).

Desse modo, pude visualizar que o ponto central do método etnográfico é de fato, a descrição densa, como Geertz (2008) aponta em Interpretação das Culturas e a interpretação dos fenômenos observados com a indispensável explicitação tanto das categorias nativas como daquelas do saber antropológico utilizado pelo pesquisador. (KANT DE LIMA, 1983). 


\section{A CULTURA DO BACHARELISMO E A ÉTICA DOCENTE}

No Brasil, o golpe de Estado que derrubou Dom Pedro II foi efetuado por segmentos de uma elite brasileira totalmente alheia aos anseios populares que jamais se preocupou com eles. O período posterior a esse golpe recebeu, dentre outras tantas, o apelido de "República dos Bacharéis", devido ao fato de que até 1930, o exercício de posições de realce na política ser exclusivo para possuidores do diploma de bacharelado. Declaradamente, a exigência de títulos acadêmicos como requisito para ocupar cargos públicos, era na verdade, apenas uma forma da elite manter os seus privilégios oriundos nos tempos do Império. Na quadra da temporalidade, essa República dos Bacharéis se encerrou em 1930, mas sua alma continuou vagando por aqui e, pouco a pouco vem ressurgindo com intensidade.

No rol deste desenvolvimento histórico, a graduação em Direito segue sendo uma das formações mais almejadas pelos estudantes, mesmo com todas as mudanças ocorridas nas últimas décadas no mercado de trabalho e com o advento das formações tecnológicas, ela ainda segue sendo bastante procurada, devido o número de concursos públicos de nível médio e superior que exigem tais conhecimentos, em particular de direito constitucional e direito administrativo. Segundo dados do Censo da Educação Superior de 2018, respectivamente, direito, pedagogia e administração são os cursos mais requisitados. ${ }^{2}$

Atualmente, o curso de Direito é ofertado somente na modalidade de bacharelado e presencial. Os cursos de bacharelado preparam, em tese, o estudante para atuar diretamente com as atividades "técnico-burocráticas" da profissão. Para o caminho da docência é recomendado que se faça Mestrado e Doutorado, por ser uma exigência de algumas universidades no Brasil, em especial das públicas. Estas credenciais, legitimam o professor, que através da sua própria pedagogia é capaz de ministrar suas aulas. Já em IES privadas, vida de regra, há a preferência por se contratar especialistas recém-formados para amenizar o "custo docente" e coloca-los para ministrar aulas de todas as disciplinas do curso, incluindo aquelas em que não possuem expertise. Em um passado não muito recente, as faculdades particulares procuravam ansiosamente por professores-doutores para autorizar o funcionamento de seus cursos, já que o

\footnotetext{
2 Direito, pedagogia e administração são os cursos com mais alunos no Brasil. Mais de $20 \%$ dos estudantes estão em uma dessas graduações, segundo dados do Censo da Educação Superior. Veja a ordem por matrículas: $1^{\circ}$ $10,8 \%$ das matrículas são em Direito $2^{\circ}-8,6 \%$ das matrículas são em Pedagogia $3^{\circ}-8,2 \%$ das matrículas são em Administração. Disponível em: http://portal.inep.gov.br/censo-da-educacao-superior Acesso em 20/04/2020
} 
MEC exigia, mas quando descobriram que estes profissionais custam caro e atrapalham o faturamento mensal da empresa, deram um jeito de substituí-los por especialistas, quando muito mestres.

Deste modo, os docentes especialistas e mestres contratos, são obrigados pela instituição de ensino a ministrar diversas disciplinas ao mesmo tempo, mesmo que não seja da sua área de expertise. Não é incomum se deparar com advogados ensinando sociologia, antropologia e filosofia por meio de mapas mentais, fluxogramas e métodos mnemônicos de memorização. Tal formato - de aulas expositivas - com leitura de códigos jurídicos encontra-se bem sedimentado no curso de direito. No relato de muitos professores que conversei, "este é o modus operandi do ensino jurídico brasileiro". Neste quesito, nota-se que a pesquisa científica (mestrado e doutorado), não é uma tradição no campo do direito, muitos docentes acham isso "firula acadêmica". Um pensamento que se coaduna, portanto, com o que as universidades privadas buscam no mercado, um professor que quer fazer um "bico" e uma complementação de renda com a docência, sem preocupação com pesquisa ou construção de um conhecimento emancipador e reflexivo.

Destarte, os profissionais da área jurídica confundem a ética do trabalho profissional com a ética do aprendizado acadêmico. A ética do trabalho profissional é uma ética utilizada nos tribunais, de combate, de construção de teses e antíteses, que servem para ganhar disputas e lides judiciais. Por outro lado, a ética acadêmica é uma ética pautada em pesquisa, produção de ciência e conhecimento. Como na nossa área, há uma estranha dificuldade em se perceber estas nuances, o ensino do direito acaba abrigando na instância acadêmica a mesma lógica da instância profissional, já que os professores só conhecem e reproduzem a ética técnico profissional. Confirmando tal afirmação, percebe-se que na área do Direito ser bem-sucedido implica em aprovação em concurso público ou ter um grande e famoso escritório de advocacia, com milhares de ações. Na visão dos operadores, isso por si só, já garante que as pessoas sejam excelentes professores.

Durante a pesquisa, quando questionava os professores porquê davam aula de disciplinas basilares do curso como se fossem dogmáticas, eles me respondiam geralmente com frases prontas de efeito: "é um modelo de ensino de sucesso", "que tem dado certo há anos", "em time que está ganhando não se mexe". De modo que, nós professores, também demonstramos a incapacidade de estranhar as práticas que utilizamos dentro do mercado de ensino. Um docente me diz que ministra aulas de muitas disciplinas distintas por questões 
meramente econômicas, "porque tem família para criar e contas para pagar"- elemento financeiro que os motiva à docência. Em perspectiva crítica, é preciso questionar para quem esse modelo de ensino têm dado certo.

A crença dos professores de que o ensino realizado assim é o único caminho, revela-se importante, porque as faculdades privadas têm um papel significativo na expansão do ensino jurídico do Brasil. Em 2017, as IES privadas correspondiam a 86,7\% do número geral de cursos de Direito, e essa porcentagem segue em crescimento ${ }^{3}$. De acordo com os dados do INEP, em 2017, havia 1.203 cursos de graduação em Direito, espalhados por 923 IES. A graduação em Direito apresenta maior oferta de vagas e é a formação mais desejada, o que supostamente requer um maior cuidado e atenção para tal formação pelos órgãos de fiscalização. Além disso, dentre as graduações, o curso de Direito apresentou uma das melhores taxas de conclusão. Neste sentido uma aluna me diz:

\footnotetext{
"Não é difícil chegar no décimo período e se formar em direito. Eu não achei e penso que meus amigos também não. Toda formação tem suas dificuldades iniciais, mas que com o tempo são superadas. Eu por exemplo tranquei uma vez por problemas financeiros e de saúde da minha mãe, o que me fez atrasar. Se não for algo assim, em cinco anos você se forma e nem vê. $O$ fato de ter aula em um turno só ajuda muito a quem trabalha, como no meu caso. Da minha turma inicial, eu me lembro que quase todos formaram, eu não sei se todo mundo atua na área, creio que não, mas formar, dá para formar de boa, sem maiores problemas". (Aluna $-10^{\circ}$ período). Grifos meus
}

Problemas distintos, como falta de renda para continuidade nos estudos e problemas de saúde com a mãe, fazem parte de um rol de entraves que podem atrasar e até mesmo inviabilizar o sonho de alguns alunos. Os traços de desigualdade social que atravessam a sociedade brasileira em seus diversos matizes não foram suficientes para que ela desistisse, isso reforça a ideia de resiliência e vontade de melhorar de vida do cidadão nacional. De tal modo, a demarcação de uma sociologia das profissões no Brasil, se evidencia por esforço próprio dentro de um mercado competitivo, entrecortado por uma cultura do bacharelismo e uma ideia de afirmação e mobilidade social, todos eles, elementos tradicionais de nossa cultura.

3Disponível em: Sinopses Estatísticas - Censo da Educação Superior - Inep/MEC http://inep.gov.br/sinopsesestatisticas-da-educacao-superior Acesso em 20/04/2020. 
Mas hoje a República dos Bacharéis não se traduz em uma parcela de poucas pessoas como nos tempos do Império, ela se revela grandiosa, com pessoas que mesmo diplomadas ainda se encontram fora da tomada de decisões políticas e condução dos interesses do país.

\section{DEMANDA POR RECONHECIMENTO E INCLUSÃO SOCIAL: "ESSE DIPLOMA $\tilde{E}$ PARA MINHA MÃE"}

O fetiche ${ }^{4}$ pela formação jurídica, e pela vontade de ser reconhecido socialmente como cidadão ou doutor, fez com que grande número de alunos sentasse nos bancos das universidades de direito em busca do tão desejado "conhecimento jurídico" e "reconhecimento social" conquistado com a formação. O desejo por um título foi motivo de chacota pública recente no nosso país, em especial na área jurídica, como bem lembra Leonardo Avritzer (2020) no artigo A elite que falsifica títulos acadêmicos. O autor destaca que o problema da nossa elite com os títulos acadêmicos é bastante amplo e envolve até mesmo a ex-presidente Dilma Rousseff, o quase ministro da educação Decotelli, entre outros casos envolvendo Deltan Dallagnol, Alexandre de Moraes e recentemente Kassio Marques, que buscaram reconhecimento e chancela em universidades no exterior, veja:

[...] Entendo este problema como derivado da maneira absolutamente atrasada como o direito continua sendo ensinado no Brasil, onde a grande maioria das pessoas sai da faculdade com pouco conhecimento jurídico, mas com fortes redes pessoais. [..] Ou seja, não se busca conhecimento nas universidades estrangeiras: busca-se autoridade em cursos relâmpago que algumas dessas universidades oferecem por motivos financeiros. Recentemente um colega de uma universidade inglesa admitiu para mim que atividades com juízes federais brasileiros viraram uma das principais fontes de financiamento do seu programa. Só tem um problema: os títulos oferecidos por essas atividades são meros certificados, sem grande valor em qualquer sistema acadêmico que preze o nome. Daí a ficção. (AVRITZER, 2020, on-line)

\footnotetext{
${ }^{4} \mathrm{O}$ fetiche se realiza porque no Brasil estar formado no ensino superior é algo mágico e sobrenatural, as pessoas após a formação, se reconhecem em um status social superior aos demais, sentindo-se acima de cidadão. Ser doutor é uma idealização, depois a realização de um sonho, por isso, faz tanto sentido e sucesso em sociedades desiguais como o Brasil.
} 
Em verdade, a busca por destaque dentro de uma sociedade desigual e hierárquica, faz com que as pessoas mintam em seus currículos e comprem cursos que não oferecem qualquer tipo de ensinamento e as vezes nem certificação. Com a formação concluída, e o diploma conquistado, seja ele na graduação, especialização, mestrado e doutorado, no Brasil, as pessoas conseguem se desigualar dos seus antigos pares e assumem um novo espaço dentro da quadra de mobilidade socioeconômica. Diferentemente, de outras sociedades mais democráticas e igualitárias, como os Estados Unidos, em que a cidadania não necessita de certificações acadêmicas para ser exercida. A lei é, portanto, igual para todos, de fato.

Por aqui, o diploma de ensino superior garante, por exemplo, o direito a prisão especial $^{5}$, o que por si só revela uma enorme conquista perante o imaginário coletivo. Com o passar dos anos, a história se repete, pessoas formadas em direito fazem questão de serem chamadas de doutores invocando o já citado decreto do tempo do Império em vigor até hoje. Referida lei criada para o curso de direito depois foi estendida para outros cursos, como medicina. ${ }^{6}$ Isso ocorre, porque a hierarquia dos cursos, influência diretamente na hierarquia das profissões e no mercado. A corrida por uma formação se faz tão grande, que no mesmo ritmo houve uma escalada na oferta destes cursos, provocando intensa massificação deles no mercado educacional. Sobre esta temática a contribuição de Ana María Ezcurra:

En suma, la masificacíon de la Educación Superior en America Latina, al igual que en Estados Unidos, supone brechas agudas en las tasas de graduación según status socioeconómico. Entonces, y más en general, a escala global, la hipótesis es que aquel ciclo notable de masificación entraña una inclusión excluydente, según clases y sectores sociales. Es decir, socialmente condicionada. (PAULA, 2011, p. 101). Grifos meus

5 O artigo 295 traz em onze incisos as categorias que possuem direito a uma prisão especial (quais sejam: ministros de Estado, governadores, diplomados por qualquer uma das faculdades superiores da República, magistrados, delegados de polícia e guardas-civis dos Estados e Territórios, ativos e inativos...). Todas essas pessoas possuem o direito de aguardar seu julgamento em um lugar diferente da prisão comum, se diferenciam dos demais por meio deste privilégio concedido nos anos de 1940 no governo ditatorial.

6 A Lei do Império de 11 de agosto de 1827, que "cria dois cursos de ciências jurídicas e sociais", afirma que os que frequentarem "os cinco annos de qualquer dos cursos, com approvação, conseguirão o gráo de bachareis formados" e diz que "haverá tambem o gráo de Doutor, que será conferido áquelles que se habilitarem som os requisitos que se especificarem nos estatutos". Disponível em: http://www.planalto.gov.br/ccivil_03/leis/lim/LIM.-11-08-1827.htm Acesso: 22/04/2020 
O fenômeno descrito pela autora é demasiadamente notado na sociedade brasileira e dialogam com as reflexões de Luís Roberto Cardoso (2018) sobre exclusão discursiva. O autor, no texto Sensibilidade cívica e Cidadania no Brasil, discute a ideia de igualdade cidadã sobre o prisma das demandas por respeito e consideração ou reconhecimento em perspectiva comparada com os Estados Unidos e França. Nos dois últimos países não precisa ser advogado ou ter formação superior para ser reconhecido como cidadão e ser sujeito de direitos. Já no Brasil, a formação jurídica viabiliza uma identidade pública respeitável, com melhor posicionamento na hierarquia social e melhor gozo de direitos. Assim, a busca pelo curso de direito se baseia na ideia de conquistar um status diferente no mundo cívico - melhor ou superior ao que se tem hoje - para de alguma forma se desigualar dos demais no espaço coletivo. (OLIVEIRA, 2018, p. 36)

No campo jurídico, se verifica que ter um diploma não é suficiente para o sucesso na carreira, necessita-se em alguns casos, de apadrinhamentos de amigos, familiares para o melhor posicionamento na carreira privada. A outra via para o sucesso é o concurso público, que dependerá do acesso aos cursinhos específicos para as carreiras que se pretende concorrer. Como identifica Bóris Maia (2019) em sua tese de doutorado acerca do "Aprendizado e tradição de conhecimento na preparação para concursos públicos", mas que no meu caso ser realizará no campo da graduação em direito. Os nossos cursos jurídicos são estruturados na pretensão de esgotamento de leis e estudo voltado para realização de questões "estilo concurso" (MAIA, 2019).

Para além deste fenômeno característico do direito brasileiro, tem-se a situação econômica dos alunos ou de seus familiares, que influencia diretamente no sucesso ou fracasso dos egressos do curso, seja na aprovação para o concurso desejado, ou na advocacia. Em uma sociedade desigual e hierarquizada, dita moderna, mas inserida em uma lógica ainda colonial, uns continuam sendo mais iguais do que os outros, e as oportunidades seguem sendo diferentes. Para exemplificar, números do CNJ de 2018 confirmam tal hipótese ao analisar o perfil sociodemográfico dos juízes brasileiros: "No que se refere ao perfil étnico-racial, a maioria [dos magistrados] se declara branca (80,3\%), 18,1\% negros (16,5\% pardos e 1,6\% pretos), e 1,6\% de origem asiática (amarelo). (CNJ, 2018, p.08). Nosso histórico escravagista explica bem estes dados reveladores da nossa desigualdade. (CNJ, 2020, on-line)

A exclusão de acesso não termina por aí, uma significativa quantidade de estudantes formados em Direito, supostamente aptos para exercer a profissão de advogado, são impedidos 
de exercê-la se não aprovados no exame de ordem. Este dado revela que a educação brasileira, em especial a jurídica, instituiu uma prática de inclusão-excludente porque formar não é garantia de emprego e a formação não é para adquirir conhecimento, mas melhorar o status social. Fazendo eclodir um processo de formação acadêmica, onde há a valorização de um diploma, como mecanismo de provável elevação do padrão de vida, sem haver, entretanto, o interesse pelo conhecimento verdadeiro, sendo este ao revés, coadjuvante. Como um aluno me diz:

\footnotetext{
"Fiz cinco anos de faculdade de Direito e serei o primeiro "doutor" de uma família de sete irmão, meus pais são semianalfabetos, por isso que falo sempre que esse diploma não é meu, esse diploma é para minha mãe. Eu vou acabar esta faculdade por honra e orgulho da minha família. Eu não vou fazer nada com esse diploma, eu já tenho uma agência de revenda de carros usados de sucesso com meu irmão na Automóvel Clube [Rua no município de São João de Meriti] esse diploma é uma conquista mais pessoal do que profissional”. (Aluno $-10^{\circ}$ período) Grifos meus
}

A passagem acima é decisiva na confirmação da hipótese teórica apresentada no trabalho de que o diploma é acima de tudo uma conquista pessoal, tendo ele um efeito de marcador social. Nesta lógica, perde-se em alguma medida, a essência de transformação da Universidade e seu poder de produzir conhecimento, emergindo um modelo de ensino montado nas bases de um saber informativo de mera reprodução e entrega de diplomas, produzindo uma cultura de certificação em massa. Mas por outro lado, mesmo que de modo implícito, fica clara na fala do aluno que o diploma serve para aquisição de um status diferenciado, tê-lo e dizer que o tem, é a forma de se afirmar em uma sociedade que estratifica seus cidadãos profissionalmente. Vide o caso da mulher de um engenheiro que discutiu com um fiscal da prefeitura do Rio, que reprimia aglomerações durante a pandemia, proferindo a seguinte fala: “ Cidadão não, engenheiro civil, formado, melhor do que você".

Estes acontecimentos, seja no âmbito da sociedade civil, ou nas entrevistas para a este artigo, parecem ser resultados de uma demanda cultural local muito própria da sociedade brasileira, que confirmam esta necessidade de desigualar para estar em um lugar de superioridade. Há, no entanto, estimada demanda por reconhecimento dos cidadãos brasileiros dentro do espaço cívico que circulam. Uma variável que parece permear diversas classes 
sociais, mas especialmente as mais populares. De maneira que essa noção de sensibilidade cívica, é imprescindível para compreender os dilemas da cidadania no Brasil.

Não se pode olvidar que o ensino jurídico com o passar do tempo veio se tornando cada vez mais acessível, diminuindo seu "caráter elitista" de outrora no perfil de seleção do aluno, possibilitando até maior convivência social com operadores jurídicos representantes de diferentes estratos sociais. Mas o formato de se ensinar ainda preserva traços de um modelo tradicional, que se atualizou para um mercado massificado de certificações vazias. O Projeto Pedagógico do Curso de Direito (PPC) da Universidade pesquisada adverte que a maior parte da clientela do Curso vem dos setores sociais populares e médios ${ }^{7}$ do município do Rio de Janeiro, que percebe o estudo do Direito como forma de mobilidade social e ascensão profissional, por isso identificamos o fenômeno da inclusão-excludente.

Nesta tentativa de minorar as desigualdades, paradoxalmente estas pessoas em busca de mais igualdade e cidadania se deparam na faculdade com "lógicas de desigualdade" inerentes a toda sociedade brasileira. Assim, os preceitos de igualdade formal preconizados pela constituição de 1988, se apresentam contraditórios frente a antológica frase de Rui Barbosa que preconiza que "A regra da igualdade não consiste senão em quinhoar desigualmente aos desiguais, na medida em que se desigualam" (BARBOSA, 1999, p. 26).

Segundo Roberto Cardoso, a regra proposta por Barbosa sugere uma forma de "tratamento igualitário" na qual os direitos seriam diferenciados (ou desigualados) de acordo com o status do cidadão. (OLIVEIRA, 2018, p.40). Ainda de acordo com o autor, mesmo que essa não seja a interpretação mais adequada para o pensamento de barbosiano, a frase é sempre acionada pelo poder judiciário quando se quer desigualar direitos. Mais uma vez, o exemplo destes usos no nosso ordenamento é o instituto da "prisão especial" para portadores de diploma de ensino em curso superior. O que distingue direitos de acordo com o status social do cidadão ${ }^{8}$. Em suma, diante destas interlocuções, não parece que alunos de curso jurídico estejam em busca de aprender seus direitos, mas sim interessados em adquirir todos os privilégios possíveis de

\footnotetext{
${ }^{7}$ Semestralmente é realizada pela universidade a pesquisa Perfil do Calouro que oportuniza esse diagnóstico. ${ }^{8}$ Para maiores esclarecimentos leia o ensaio de Teixeira Mendes (2005) sobre igualdade à brasileira. Na realidade, o acesso à prisão especial foi ampliado nos últimos anos, e abrange outras categorias além dos portadores de diploma superior. Embora este não seja o único exemplo de alocação de direitos conforme o status social do cidadão, é o mais conhecido e aquele que melhor expressa problema
} 
serem alcançados dentro da sociedade brasileira por meio da mobilidade que o status educacional pode promover no status cívico.

Roberto Kant de Lima no texto "Carnavais, malandros e heróis: O dilema brasileiro do espaço público" contido no livro O Brasil não é para principiantes, destaca a existência de modelos de hierarquia (includentes e excludente) para compreender algumas lógicas de funcionamento do direito em diferentes sociedades. O que aparece no campo do ensino jurídico de forma semelhante quando observamos alguns desfechos. E dialoga intimamente com o que Cardoso Oliveira (2018) aponta, pois demonstra as distinções de ordem pública e social para a manutenção ou reprodução dos modelos postos. De acordo com Kant de Lima o modelo de hierarquias includentes, permitem, teoricamente, que todos os participantes de um determinado universo possam chegar a todas as posições da estrutura, por outro lado, o modelo de hierarquias excludentes, adverte que nem todos poderão chegar ao topo da hierarquia, pois não há espaço para tal. (KANT DE LIMA. 2000, p. 116).

Desta forma, é possível se perceber dois modelos pré-existentes para pensar a ordem pública e social. O primeiro - includente - se pauta no individualismo, no igualitarismo, na oposição, na igualdade pela diferença, e no modelo do paralelepípedo. O segundo - excludente - se baseia no holismo, na hierarquia, na complementariedade, na igualdade (por semelhança) e no modelo piramidal. O primeiro modelo é característico de sociedades oriundas da tradição anglo-americana, que ensinam maneiras de resolver seus conflitos baseando-se em negociações (barganha) e arbitragem, por exemplo. No modelo oposto, característico da Europa Continental, em especial do reino de Portugal, "a hierarquia depende da harmonia e a regra é que as partes são, em princípio, desiguais e complementares, elementos integrantes de uma escala infinita de gradações possíveis". Nestes casos, as conciliações são utilizadas para dissolver o conflito e o julgamento para encontrar um culpado, sempre em busca da "verdade real”. (KANT DE LIMA, 2000, p. 118). Sendo, portanto, este modelo hierárquico excludente, o que vige na sociedade brasileira. O paradoxo reside em algumas normas constitucionais que pretendem aplicar o modelo da igualdade inclusiva e do paralelepípedo. Logo, em nosso país, existem duas lógicas contrapostas e contraditórias convivendo ao mesmo tempo. A lógica legal da suposta igualdade prevista no art. $5^{\circ}$ da CRFB e a lógica social da desigualdade.

Os modelos descritos acima, são a base da formação cultural afeta ao bacharelismo do império brasileiro. A formação moderna, ainda é colonizada de ideais do passado que historicamente visavam formar pessoas destinadas a trabalhar com atividade burocrática para 
os quadros da administração pública nacional. E isso é revelado com a pesquisa de campo. $\mathrm{Na}$ atualidade, a expansão desenfreada dos cursos jurídicos, fez com que cada vez mais um cargo público fosse objeto de desejo de diversas classes sociais (em especial as mais populares - como constatação da própria IES), pois a maioria destes cargos se associa a relevantes regalias e privilégios comum a alguns servidores.

\section{HIERARQUIAS, STATUS CÍVICO E MOBILIDADE SOCIAL}

Entretanto, o grande desafio é como se alcançar este topo da hierarquia e o status cívico desejado no seio social. Para isso é preciso graduar-se, passar na OAB e preparar para o concurso público ou para o mercado de trabalho, configurando uma trajetória longa de estudos. Assim, mesmo diante de anos de estudo, existem contradições observadas pelos operadores do campo, que narram as dificuldades de pessoas recém-formadas para o manejo dos rituais de justiça e dos entraves legais. Conforme um professor e juiz de direito me explica, essa dificuldade dos advogados novatos é uma característica da formação jurídica brasileira e ela deságua em um problema de ordem prática para o nosso sistema judicial:

\footnotetext{
Muitos advogados recém-formados e também com algum tempo de formado, não sabem como conduzir e agir em uma audiência, por exemplo. É nítido o despreparo. Não conseguem interpretar uma sentença, ou um despacho. Perdem prazos porque não sabem o que requerer. Mas estes são problemas técnicos. Existem os de ordem teórica, advogados que não sabem escrever por isso não conseguem pedir o que querem. E juiz não pode advogar para parte nenhuma. Eu realmente não tenho solução para este complexo problema. Mas fico refletindo se isso não seria o reflexo de uma graduação fácil, onde o objetivo inicial do aluno era só o diploma de ensino superior? (Professor-juiz de direito) Grifos meus
}

Diante da exposição do magistrado queria destacar dois pontos interessantes. Primeiro, a constatação de que o aluno não aprende a advogar, porque a faculdade não oferece esse "conhecimento técnico" como é exigido para a prática dos Tribunais. Lembrar que a faculdade enquanto pessoa jurídica, não ensina nada a ninguém, pois a faculdade existe pelos professores e pelos alunos. Logo, quando se julga que o aluno não aprendeu, é possível fazer uma reflexão 
sobre o que (não) ensinou também. A fala do juiz lança luz para a ideia de que a faculdade não ensina a prática do direito necessária para atuar nos tribunais, contrastando com essa ideia, verifica-se um vácuo já que o PPC do curso da Instituição, aduz a integração entre teoria e prática. ${ }^{9}$ Ressalta-se que o direito não apresenta teorias como em outras áreas, apenas saberes dogmáticos e doutrinários, logo, fica difícil evidenciar tal integração. No cenário em que os operadores considerariam a doutrina como sendo uma "teoria", também não haveria a articulação com os saberes práticos, uma vez que os alunos dizem não aprenderem substancialmente no âmbito dos NPJ e os professores, como o da fala acima, afirmam que eles não sabem o básico.

O segundo, foi apontar que a "graduação fácil" não é combatida pelo suposto filtro da OAB para seleção de bacharéis aptos ao ofício da advocacia. Noutras palavras, o problema da construção do conhecimento no direito se revela para além da formação no momento da graduação. Ele se consubstancia em elementos do passado, das tradições e das reproduções, e atualmente dos anseios do mercado. De modo que este modelo, seguirá se perpetuando nos sistemas avaliativos externos à graduação, como o exame de ordem e os certames de concurso público. Assim, as exigências de conteúdos legalistas previstos em normas estáticas não ensinam os alunos a pensar em soluções para os conflitos dinâmicos da vida real. Neste sentido José Eduardo Faria afirma que os alunos:

[...] ao deixarem a faculdade com o diploma nas mãos, terão a amargura de descobrir o descompasso entre a (in) formação profissional recebida e o universo de conflitos reais, não contando assim com o preparo teórico e prático suficientes para reordenar seus conceitos e ajustar-se a uma realidade nova e responsável por inúmeras transformações nas funções do direito. (FARIA, 1987, p.51)

Esse descompasso apontado por Faria, pode, em alguma medida, potencializar o binômio da inclusão-excludente que destaquei acima e reforçar o que o juiz exalta na sua interlocução comigo. O magistrado também me orienta, após nossa conversa, a ler os escritos do professor Sérgio Adorno, pois extrairia dali valiosas reflexões para minha pesquisa. Eu já conhecia o trabalho do referido professor em "Os aprendizes do poder: o bacharelismo liberal

\footnotetext{
${ }^{9}$ Missão do curso: "Assim, o Curso privilegia a integração teoria/prática, proporcionando instrumental para o desenvolvimento de uma aprendizagem autônoma, a fim de permitir ao egresso a atuação na advocacia privada, em outras carreiras jurídicas públicas [...]"
} 
na política brasileira (1988) " e compreendia a importância dele no debate do bacharelismo nacional e a formação das carreiras profissionais no Brasil.

Este foi o cenário em que, no Brasil, deu-se o surgimento do que Sérgio Buarque de Holanda denominou de a "praga do bacharelismo" (HOLANDA, 1995, p. 156). Conveniente notar que o diploma de bacharel não habilitava apenas para o exercício da profissão de advogado e das carreiras jurídicas, uma vez que era o instrumento próprio para o ingresso em uma série de outras atividades também, tais como o jornalismo, o magistério, a chefia de órgãos públicos ${ }^{10}$ etc.

O bacharelismo possui hoje uma conotação pejorativa e caricatural denominado por Paulo Roberto Medina de "bacharelice”. (MEDINA, 2009) e usado para caracterizar pessoas que se valem de um palavreado vazio, pretensioso e de uma retórica invisível como forma de demonstrar uma falsa eloquência e compreensão das coisas. A dinâmica deste fenômeno histórico e atual é explicitada:

\begin{abstract}
Após 1930, o bacharel em Direito passou a perder os espaços antes cativos da burocracia estatal para outros profissionais (tecnocratas), acentuando-se o fenômeno durante o regime militar pós-64. A partir daí a proliferação dos cursos jurídicos de qualidade precária serviu aos interesses da nova ordem, em se formarem profissionais burocráticos para serem absorvidos pelas funções subalternas e para amortecerem a pressão da classe média, ansiosa por ascensão social facilitada pelo diploma universitário. (LOBO, 1996, p.12)
\end{abstract}

E talvez este movimento seja bastante encampado pelas faculdades de direito na atualidade mesmo, o que poderia estar de acordo com a impressão do magistrado entrevistado. Parece então, que a cultura do bacharelismo colaborou para a formação de uma cultura permanente de modelo formalista, retórico, legalista e individualista, aos moldes do ensino jurídico colonial:

\footnotetext{
${ }^{10}$ Desde cedo, os cursos jurídicos nasceram ditados muito mais pela preocupação de se constituir uma elite política coesa, disciplinada, devota às razões do Estado, que se pusesse à frente dos negócios públicos e pudesse, pouco a pouco, substituir a tradicional burocracia herdada da administração joanina, do que pela preocupação em formar juristas que produzissem a ideologia jurídico-política do Estado Nacional emergente. (ADORNO, 1988, p. 236)
} 


\begin{abstract}
"No fundo todo mundo que faz direito sonha em ter um bom cargo público, eu fui assim. Negar isso é leviandade. Pergunte em uma sala de primeiro período e veja quantos querem ser juízes, promotores, delegados, muitos dirão que é o sonho da vida deles, que estão ali por isso. Todos buscam algum prestígio, reconhecimento e dinheiro, é intrínseco à vida estes desejos. Poucos querem ser advogados ou professores. Existe um fetiche no Brasil por cargos públicos, isso faz parte da nossa história está nas nossas entranhas. Só que nós professores, sabemos que não tem vaga para todo mundo para ser servidor público e que estes concursos aprovam somente pessoas muito aptas ao crivo deles". (Professora-doutora)
\end{abstract}

Pelo relato da professora fica evidente que a cultura do bacharelismo ainda resiste na nossa formação histórica enquanto nação. A aprovação no concurso é sinônimo de status, é o que almeja a grande massa de alunos. Fazer parte de órgão da administração pública, seja como um burocrata, ou um tecnocrata é um sonho dourado. A preleção da professora se entrelaça com o que uma aluna fala para outras amigas no brinde de formatura que pude acompanhar em uma festa idealizada pelos formandos de 2019.2: “agora acabou a pobreza, daqui para frente é só glamour, sou advogada, linda loira e rica” (risos). O momento da formatura é simbólico pois marca um período de mudanças, qual seja de uma possível ascensão social e econômica desejada - um ritual de passagem.

A construção destes maneirismos se constata na observação empírica e na cultura histórica do bacharelismo que colabora para a disseminação destes outros costumes também valorizados pelo campo jurídico. Dentre muitos rituais, repletos de significados, o mais marcante para mim foi durante uma formatura visualizar familiares entregando anéis de rubi ${ }^{11}$ a filhos e netos, bacharéis em Direito. Dentre os presentes dotados de simbologia, o mais desejado é uma peça decorativa que retrata a justiça vendada como símbolo de imparcialidade: a balança, indicando o equilíbrio e a ponderação dos argumentos contra e a favor dos acusados, e a espada como um sinal de força.

Para além dos elementos representativos citados, a ideia de adestramento, perpetrada pela prática docente, promovida pelo ensino jurídico ao longo dos anos, não foi superada mesmo com as transformações sociais, políticas e econômicas experimentadas pelo país. A democratização, mudou o perfil do aluno-cliente, mas não alterou o desejo de ocupar

$11 \mathrm{O}$ rubi é uma das pedras mais valorizadas e desejadas do mundo. Amplamente utilizada para criar joias de beleza única, ela é a gema preciosa que representa o curso de direito. Sempre vermelho e muito raro, o rubi simboliza o dom da palavra, escrita ou falada. Ele também é relacionado à proteção, força e ao entusiasmo. Por carregar estes simbolismos, o rubi é a pedra perfeita para representar os futuros bacharéis em direito. Disponível em: $\quad$ https://blog.poesie.com.br/aneis-de-formatura/qual-o-simbolo-do-direito-seu-significado-e-anel-deformatura-do-curso/\#ixzz6lsUERvzi Acesso em: 08/02/2021. 
determinado espaço elitista. Mudou, mas manteve seu caráter conservador. As pessoas passaram a ver no curso superior em direito uma possibilidade de ascensão social, conforme mostra a fala da aluna entrevistada acima. No mesmo sentido, um outro aluno me diz:

\footnotetext{
"Eu sou técnico em contabilidade. Sempre atuei no ramo. Mas vi no curso de direito a possibilidade de melhorar de vida. A contabilidade foi o que pude fazer naquela época em que trabalhava para ajudar meus pais. Hoje, graças a Deus eu posso fazer o curso que sempre quis. Em breve, quando eu me formar tenho certeza que aliando meus conhecimentos na área de contabilidade e a minha paixão por direito tributário, darei uma condição de vida melhor para minha família. (Aluno - $10^{\circ}$ período)
}

O bacharel em direito, ou um estudante recém-formado, vislumbra ser um funcionário público ou um advogado de sucesso, em ambos os casos, obrigatoriamente, eles se relacionaram no exercício da atividade profissional, com instituições de poder e burocracias estatais, relações estas, que fizeram aparecer um hábito-jurídico-político estudantil valorizador de um saber demasiadamente dogmático e acrítico, denominado de senso comum teórico ${ }^{12}$ dos juristas (WARAT, 2004) em detrimento de uma aproximação com a realidade social. Essa constatação da pesquisa vai na contramão do que o próprio PPC do curso promete quando fomenta a integração entre teoria e prática durante o curso.

Uma das informações que podem ser assinaladas como integrantes da função conservadora do ensino jurídico é a baixa quantidade de pesquisas de matriz empírica relacionadas ao Direito no âmbito da graduação naquela universidade e a ausência de uma adaptação às realidades sociais e regionais.

\section{CONCLUSÃO}

O presente artigo, compreendeu que o direito não se restringe a um caminho de construção de saberes jurídicos apenas, mas flerta com a construção de uma nova forma de se pensar e se posicionar socialmente e civicamente. Nota-se também como o acesso ao

\footnotetext{
${ }^{12}$ Leia-se: senso comum doutrinário.
} 
conhecimento jurídico, seja na graduação ou nos cursos preparatórios, associa-se ao exercício dos direitos de cidadania no discurso dos entrevistados. A conquista do diploma equivale a uma liberdade e a um direito que antes parecia abafado ou inexistente.

É possível dizer que a formação em Direito também ensina outros assuntos para além do conhecimento jurídico-dogmático. Ensina uma nova percepção de mundo e de comportamento social. Um estilo formal de roupas como uma categoria cultural de vestimenta, uma forma gestual, uma maneira de falar apropriada, com um linguajar rebuscado, edifica uma gramática própria e marca a hierarquia dentro do Direito, que é naturalizada dia a dia por meio das rotinas judiciárias e que compõe a lógica do bacharel em atrelado a uma instância de poder.

Assim, a formação técnica-profissional-universitária, muito embora conceda algum preparo no campo do ensino formal, não é garantia de empregabilidade e sucesso no trabalho. Estes prestígios só se conquistam, quando muito, com o passar do tempo e com muito trabalho, estudo e dedicação. Portanto, se o objetivo é a conquista do diploma para satisfazer os anseios de mães ou de pais e ainda como símbolo de ascensão social, sem fundamento fica o comprometimento acadêmico reflexivo e crítico do aluno. O que acaba sendo uma contradição se olharmos para os objetivos específicos delineados no Proposta Pedagógica do Curso como a intenção de promover um ensino voltado para: "articular a teoria e a prática a partir de uma análise crítica e da problematização da realidade. "

Conclui-se também que o mesmo mercado que produz estas oportunidades, determina uma razão ambivalente que chamei de inclusão-excludente, devido ao elevado número de alunos concluintes que se tornam advogados e não são absorvidos pelo mercado de trabalho. Mas não só por isso, ela escancara também que a tradição bacharelesca da nossa sociedade, por meio da cultura jurídica que desenvolvemos, provoca uma demanda por inclusão em uma nova camada social. Ou seja, a busca pelo diploma se relaciona com o desejo de reconhecimento cívico e a necessidade de fazer valer os direitos de cidadania. No fundo, ficou nítido, que os estudantes querem adquirir uma inclusão discursiva objetiva para melhor se acomodarem socialmente.

O diploma de ensino superior é um escudo para uma provável mobilidade no status social. Por outro lado, o ensino do direito também revela e abriga, algumas frustrações e exclusões de alunos que não obtêm aprovação em concursos públicos ou no exame de ordem e são automaticamente descartados. A sociedade de mercado, de modelo capitalista em que as 
empresas privadas do ramo de ensino atuam, não são comprometidas com quaisquer obrigações de resultados perante os seus alunos. Não existe contrato de prestação de ensino jurídico que prometa aprovação na $\mathrm{OAB}$ ou em algum concurso. $\mathrm{O}$ fato aqui é apenas notar que o percurso não é consistente para se atingir o fim desejado por muitos, é necessária complementação com cursinhos preparatórios ao longo da jornada para aquisição de saberes específicos

\section{REFERÊNCIAS BIBLIOGRÁFICAS}

ADORNO, Sérgio. Os aprendizes do poder: o bacharelismo liberal na política brasileira. Rio de Janeiro: paz e terra, 1988.

AVRITZER, Leonardo. A elite que falsifica títulos acadêmicos. Disponível em: https://jornalggn.com.br/artigos/a-elite-que-falsifica-titulos-academicos-por-leonardo-avritzer/ Acesso em 20/04/2020.

BARBOSA, Oração aos Moços. Edição popular anotada, por Adriano da Gama Kury, $5^{\text {a }}$ edição, Rio de Janeiro, 1999.

FOOTE-WHYTE, William. Treinando a observação participante. In: A. Zaluar (org.) Desvendando Máscaras Sociais. Rio de Janeiro: Livraria Francisco Alves Editora S.A., 1975.

HOLANDA, Sérgio Buarque de. "Corpo e alma do Brasil" - Raízes do Brasil, São Paulo, Companhia das Letras, 1995 e 2006.

FARIA, José Eduardo. A reforma do ensino jurídico. Porto Alegre: Sérgio Antonio Fabris Editor, 1987.

KANT DE LIMA, Roberto. Por uma Antropologia do Direito no Brasil. In: Falcão, Joaquim de Arruda. Pesquisa Científica e Direito. Recife: Massangana, 1983.

Roberto. Carnavais, malandros e heróis: O dilema brasileiro do espaço público. In: Laura Graziela Gomes; Livia Barbosa; José Augusto Drummond. (Org.). O Brasil não é para Principiantes. 1ed.Rio de Janeiro: FGV, 2000, v. 1, p. 105-124.

INEP, Instituto Nacional de Estudos e Pesquisas Educacionais Anísio Teixeira. Disponível em: http://portal.inep.gov.br/censo-da-educacao-superior Acesso em 20/04/2020

LOBO, Paulo Luiz Neto (Coord). Uma cartografia dos problemas In: ENSINO Jurídico: Diagnósticos, perspectivas e propostas. 2. ed. Brasília: Conselho Federal da OAB, 1996.

MAIA e SILVA, Bóris. SUJEITOS DE ESTADO Aprendizado e tradição de conhecimento na preparação para concursos públicos da burocracia fiscal. Tese de Doutorado apresentada no PPGA/UFF, Niterói, 2019. 
MEDINA, Paulo Roberto de Gouvêa. Do bacharelismo à bacharelice: reflexos desses fenômenos nos cursos jurídicos, ao longo do tempo. In: ENSINO Jurídico: literatura e ética. Brasília: OAB, 2009.

OLIVEIRA, Luís Roberto Cardoso. Sensibilidade Cívica e Cidadania no Brasil. Antropolítica: Revista Contemporânea de Antropologia, v. 44, p. 34-63, 2018.

PAULA, Maria de Fátima Costa de. Educação superior e inclusão social na América Latina: um estudo comparado entre Brasil e Argentina, In: Maria de Fátima Costa de PAULA \& Norberto FERNÁNDEZ LAMARRA. (Orgs). Reformas e democratização da educação superior no Brasil e na América Latina. Aparecida (SP): Ideias \& Letras, 2011

PIRES, E.L. Metamorfoses e regulação. O mercado de trabalho no Brasil dos anos 80. São Paulo, 342 p. Tese (Doutorado). Faculdade de Filosofia, Letras e Ciências Humanas da USP, 1995.

VENANCIO FILHO, Alberto. Das Arcadas ao Bacharelismo - 150 anos de ensino jurídico no Brasil. São Paulo: Perspectiva, 2011.

WARAT, Luis Alberto. Epistemologia e ensino do direito: o sonho acabou. Coord. Orides Mezzaroba, Arno Dal Ri Júnior, Aires José Rover, Cláudia Servilha Monteiro. Florianópolis: Fundação Boitex, 2004. 